\title{
QUANTITATIVE DETERMINATION OF CRIZOTINIB IN HUMAN PLASMA WITH HIGH- PERFORMANCE LIQUID CHROMATOGRAPHY AND ULTRAVIOLET DETECTION
}

\author{
BABY NALANDA REVU ${ }^{1}$, SRINIVASA RAO ATLA ${ }^{1 *}$, GOWRI SANKAR DANNANA ${ }^{2}$ \\ ${ }^{1}$ Department of Pharmaceutical Analysis and Quality Assurance, Shri Vishnu College of Pharmacy (Affiliated to Andhra University), \\ Andhra Pradesh, India. ${ }^{2}$ Department of Pharmaceutical Analysis and Quality Assurance, College of Pharmaceutical Sciences, Andhra \\ University, Visakhapatnam, Andhra Pradesh, India. Email: drasrpharma@gmail.com
}

Received: 22 August 2018, Revised and Accepted: 10 October 2018

ABSTRACT

Objective: A rapid, sensitive, selective, and reproducible reversed-phase high-performance liquid chromatographic method has been developed and validated for the determination of crizotinib (CRZ), a tyrosine kinase inhibitor for targeted therapy of anaplastic lymphoma kinase-positive non-smallcell lung cancer.

Methods: The chromatographic separation was carried out in an isocratic mode on an YMC ODS $\mathrm{C}_{18}$ column with a mobile phase consisting of methanol and water containing $0.1 \%$ orthophosphoric acid in the ratio of $50: 50 \mathrm{v} / \mathrm{v}$ at a flow rate of $0.6 \mathrm{ml} / \mathrm{min}$. The run time was maintained for $10 \mathrm{~min}$ and detection was monitored at $267 \mathrm{~nm}$. The method involved reproducible liquid-liquid extraction of drug from human plasma using diethyl ether as extracting solvent.

Results: CRZ and internal standard retention times were 6.86 and 7.94 min, respectively. Calibration curves were linear over a concentration range of 20.41-2041.14 ng/ml with correlation coefficient 0.9994 . The lower limit of quantification for CRZ in plasma was $20 \mathrm{ng} / \mathrm{ml}$. No endogenous substances were found to interfere with the peaks of drug and internal standard. The intra- and inter-day precision was < $9.0 \%$ and the accuracy ranged from $97 \%$ to $112 \%$ over the linear range. All stability studies showed that CRZ in plasma sample was stable.

Conclusion: This method was found to be simple, selective, precise, accurate, and cost-effective. Hence, the method can be successfully applied to analyze the CRZ concentration in plasma samples for pharmacokinetic and bioequivalence studies.

Keywords: Tyrosine kinase inhibitor, Anaplastic lymphoma kinase, Crizotinib, Liquid-extraction, Pharmacokinetics.

(C) 2019 The Authors. Published by Innovare Academic Sciences Pvt Ltd. This is an open access article under the CC BY license (http://creativecommons. org/licenses/by/4. 0/) DOI: http://dx.doi.org/10.22159/ajpcr.2019.v12i2.29272

\section{INTRODUCTION}

Anaplastic lymphoma kinase (ALK) is a receptor-type tyrosine kinase that belongs to the insulin receptor superfamily and alterations in the ALK gene including chromosomal translocations have been implicated in the development of ALK-positive human cancers. Crizotinib (CRZ) is an orally available aminopyridine-based inhibitor of the receptor tyrosine kinase ALK and the c-met/hepatocyte growth factor receptor with antineoplastic activity [1]. CRZ (Fig. 1) is the first targeted therapy for the treatment of ALK-positive non-small-cell lung cancer [2,3]. In a Phase I pharmacokinetic study evaluation of CRZ, a single $250 \mathrm{mg}$ dose achieved a maximum drug concentration in $4 \mathrm{~h}$ following the dose, with a mean apparent terminal half-life of approximately $42 \mathrm{~h}$ [4]. At present, a combination of CRZ and dasatinib is being used for treating high-grade glioma. Due to pharmacokinetic interaction between these drugs, as CRZ is an inhibitor of cytochrome P4503A. Hence, a reliable and sensitive analytical method for the determination of CRZ is much needed for further pharmacokinetic studies. Literature review revealed that CRZ was assayed in plasma by liquid chromatography coupled with tandem mass spectrometry [5-9], fluorescence detection [10]. Spectrofluorimetry was reported in biological fluids [11]; highperformance liquid chromatography (HPLC) method has been reported for the determination of CRZ in dosage form [12]. Although some of these methods provide high sensitivity and specificity, tedious extraction techniques and expensive technology are a major hindrance for their practical implementation. Therefore, a simple HPLC method with a routine extraction procedure is desirable. Hence, the present work was designed to develop and validate an HPLC method with ultraviolet (UV) detection for the determination of CRZ in human plasma.

\section{METHODS}

Chemical reagents

CRZ (purity $98.00 \% \mathrm{w} / \mathrm{w}$ ) was purchased from Celon Laboratories (P) Ltd., zidovudine (used as internal standard, purity $99.5 \% \mathrm{w} / \mathrm{w}$ ) is purchased from Hetero Drugs Ltd., Hyderabad, India. Methanol, acetonitrile (HPLC grade), orthophosphoric acid, and diethyl ether were purchased from Merck Ltd., Mumbai, India. All the other reagents used were analytical grade. All aqueous solutions were prepared using deionized water, processed through a Milli- $Q$ water purification system (Millipore, USA). Human $\mathrm{K}_{3}$ ethylenediaminetetraacetic acid (EDTA) plasma was collected from Sri Laxmi Sai Clinic, Hyderabad, India.

\section{Instrument and chromatographic conditions}

The chromatographic system consisted of a Shimadzu Class VP Binary pump LC 10ATvp, SIL-10ADvp autosampler, CTO-10Avp Column Temperature Oven, and SPD-10Avp UV-Visible detector. All the components of the system were controlled using SCL-10Avp System Controller. Data acquisition was done using LC solutions software. Chromatographic separations were accomplished using an YMC ODS C18 $(250 \mathrm{~mm} \times 4.6 \mathrm{~mm}, 5 \mu \mathrm{m})$ column. All determinations were carried out at room temperature. The mobile phase was composed of a mixture of 50 parts of methanol and 50 parts of water (containing $0.1 \%$ orthophosphoric acid). The mixture was filtered through a $0.45 \mu \mathrm{m}$ Whatman membrane filter under vacuum and then degassed by ultrasonication. The mobile phase was pumped isocratically at a flow rate of $0.6 \mathrm{ml} / \mathrm{min}$ during analysis at ambient temperature. Peaks were monitored by a UV detector adjusted at $267 \mathrm{~nm}$. Quantification of CRZ was obtained by plotting CRZ to internal standard peak area ratios as a function of concentrations. 


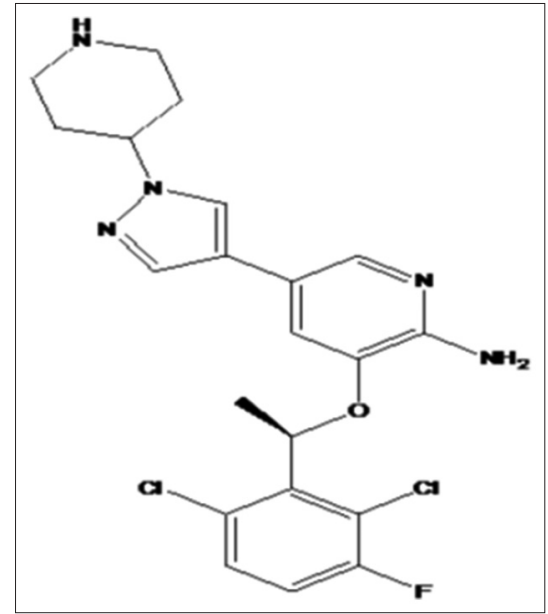

Fig. 1: Chemical structure of crizotinib

\section{Calibration and quality control (QC) sample preparations}

Stock solutions were prepared by dissolving CRZ and IS in methanol to a concentration of $1 \mathrm{mg} / \mathrm{ml}$. The stock solution of CRZ was further diluted with $50 \%(\mathrm{v} / \mathrm{v})$ aqueous methanol to get working standard solutions having concentrations of $0.41,1.63,8.16,24.49,32.66$, and $40.82 \mu \mathrm{g} / \mathrm{ml}$. Aliquots of $950 \mu \mathrm{l}$ of drug-free $\mathrm{K}_{3}$-EDTA human plasma were spiked with $50 \mu \mathrm{L}$ of working standard solutions to get calibration curve (CC) standards containing 20.41, 81.65, 408.23, 1224.68, 1632.91, and $2041.14 \mathrm{ng} / \mathrm{ml}$ of CRZ. QC samples were prepared separately and pooled at three different concentrations level $(61.23,995.05$, and $1439.00 \mathrm{ng} / \mathrm{ml}$ ) as low, medium, and high QC (LQC, MQC, and HQC) samples, respectively, to evaluate the intra- and inter-precision and accuracy of this method. All samples were stored in a freezer at $-20^{\circ} \mathrm{C}$ until analysis.

\section{Sample preparation}

The extraction of the plasma samples involved liquid-liquid extraction (LLE) process. For processing, the stored spiked samples were withdrawn from the freezer and allowed to thaw at room temperature. An aliquot of $200 \mu \mathrm{l}$ was then transferred to pre-labeled $2.0 \mathrm{ml}$ polypropylene centrifuge tubes. Internal standard dilution, $25 \mu \mathrm{l}(5 \mu \mathrm{g} / \mathrm{ml})$ was then added and mixed. To this solution, $1.0 \mathrm{ml}$ of diethyl ether was added to extract the drug and internal standard. The samples were then kept on a reciprocating shaker and allowed to mix for $20 \mathrm{~min}$. Samples were then centrifuged at $5000 \mathrm{rpm}$ for $5 \mathrm{~min}$ to effect phase separation. The supernatant solution, $0.8 \mathrm{ml}$ was then transferred into pre-labeled polypropylene tubes and was allowed to evaporate to dryness under a nitrogen atmosphere at the constant temperature of $40^{\circ} \mathrm{C}$. The dried residue was then dissolved in $100 \mu \mathrm{l}$ of mobile phase and transferred into vials for chromatographic analysis. The autosampler temperature was maintained at $4^{\circ} \mathrm{C}$ throughout the analysis.

\section{Validation of quantitative HPLC method}

The reversed-phase HPLC (RP-HPLC) method was validated according to the US Food and Drug Administration (FDA) guidelines on bioanalytical method validation [13]. The following parameters were evaluated: Selectivity, CC regression model, accuracy and precision, recovery from biosamples, the stability of analyte in the stock solution under the entire period of storage, and processing conditions. Selectivity was designed to investigate whether endogenous constituents and other substances in existing samples would interfere with the detection of CRZ and IS. It was studied by comparing the chromatograms of six different batches of human blank plasma with the corresponding spiked plasma.

The linearity of the CC in human plasma was confirmed by plotting the Peak area ratio of drug/IS versus the corresponding CRZ concentration with least squares linear regression analysis. Interday and intraday accuracy and precision were evaluated by analysis of QCs at three levels.
The recoveries of CRZ from the extracted samples were estimated by correlating the known concentrations of plasma samples. This whole process was recapitulated for concentration levels of 61.23, 995.05, and $1439.00 \mathrm{ng} / \mathrm{ml}$, which represent the LQC, MQC, and HQC standards, respectively [14].

The chemical stability of any compound in stock solution and biological samples is a critical parameter for its further development. Stock solution stability, freeze-thaw stability, benchtop stability, autosampler stability, and long-term stability was conducted to determine the stability of CRZ in plasma. For the determination of CRZ stability, spiked controls in human plasma were made at 61.23 and $1439.00 \mathrm{ng} / \mathrm{ml}$ concentrations, representing LQC and $\mathrm{HQC}$, respectively, each with three sets of replicates.

\section{RESULTS AND DISCUSSION}

Several parameters were examined for the optimization of HPLC analysis of CRZ in human plasma. Optimization was achieved by monitoring varying RP columns, mobile phase systems, flow rate, wavelength, and using the extraction method. The first step in method development was the selection of the optimal analytical column. Different columns were tested for their ability to separate the analyte. The columns that were tested included an Agilent Zorbax C18, Phenomenex Prodigy (150 mm $\times 4.6 \mathrm{~mm}$ i.d), Phenomenex C18 $(250 \times 4.6 \mathrm{~mm}$ i.d), and finally, an YMC ODS C18 (250 $\mathrm{mm} \times 4.6 \mathrm{~mm}$ i.d) column, which provided the best separation efficiency. For the mobile phase, different mixtures of methanol, acetonitrile, and water were tested. The mobile phase that gave optimal separation from plasma endogenous peaks was a 50:50 mixture of methanol and water containing $0.1 \%$ orthophosphoric acid $(\mathrm{v} / \mathrm{v})$. The flow rate of the method was optimized at $0.6 \mathrm{ml} / \mathrm{min}$. The column temperature was maintained at $25^{\circ} \mathrm{C}$. In addition to this, UV spectra of individual drugs were recorded in the wavelength range from $200 \mathrm{~nm}$ to $400 \mathrm{~nm}$. The choice of the wavelength of $267 \mathrm{~nm}$ was considered satisfactory, permitting the detection of CRZ with adequate sensitivity. This analytical method requires simple chromatographic conditions including the use of mobile phases with the small percentage of organic solvent in the absence of gradient programs [15].

It was difficult to find a compound to be used as an internal standard. Different compounds were investigated such as emtricitabine, suvorexant, metoprolol, levofloxacin, and valsartan. However, these drugs have long retention time or highly broad peaks, eluted early, and interfered with CRZ or plasma peaks. Finally, zidovudine was found to be the most appropriate internal standard under the separation condition. For the biological samples cleanup, some of the HPLC methods used methanol or acetonitrile to precipitate the protein. The advantages of this procedure are speed and ease, but the disadvantage is incomplete precipitation of the plasma protein; also, the final organic phase contains not only endogenous substances that are soluble in the solvent but also some water-soluble compounds which badly affect separation efficiency and may damage HPLC column [16].

When LLE was performed, using different solvents were tert-butyl methyl ether, ethyl acetate, dichloromethane, and hexane, it was observed that both the analyte and IS were comparably extracted and good recovery was obtained with diethyl ether. LLE method is usually devoid of polar interferences, thus rendering the sample clean for analysis. The noise is usually absent or at the minimum as compared to precipitation technique. It requires an only a small volume of plasma $(200 \mu \mathrm{l})$. Due to the LLE method of extraction, the baseline noise is minimal. Matrix effects are not observed. Under the chromatographic conditions described, the retention time for extracted peaks of CRZ and IS was 6.86 and $7.94 \mathrm{~min}$, respectively.

\section{Selectivity}

Typical chromatograms obtained from blank human plasma and the plasma spiked with CRZ and IS are shown in Fig. 2, which indicates that no peak of any endogenous compound appeared at the retention time of CRZ and zidovudine. 


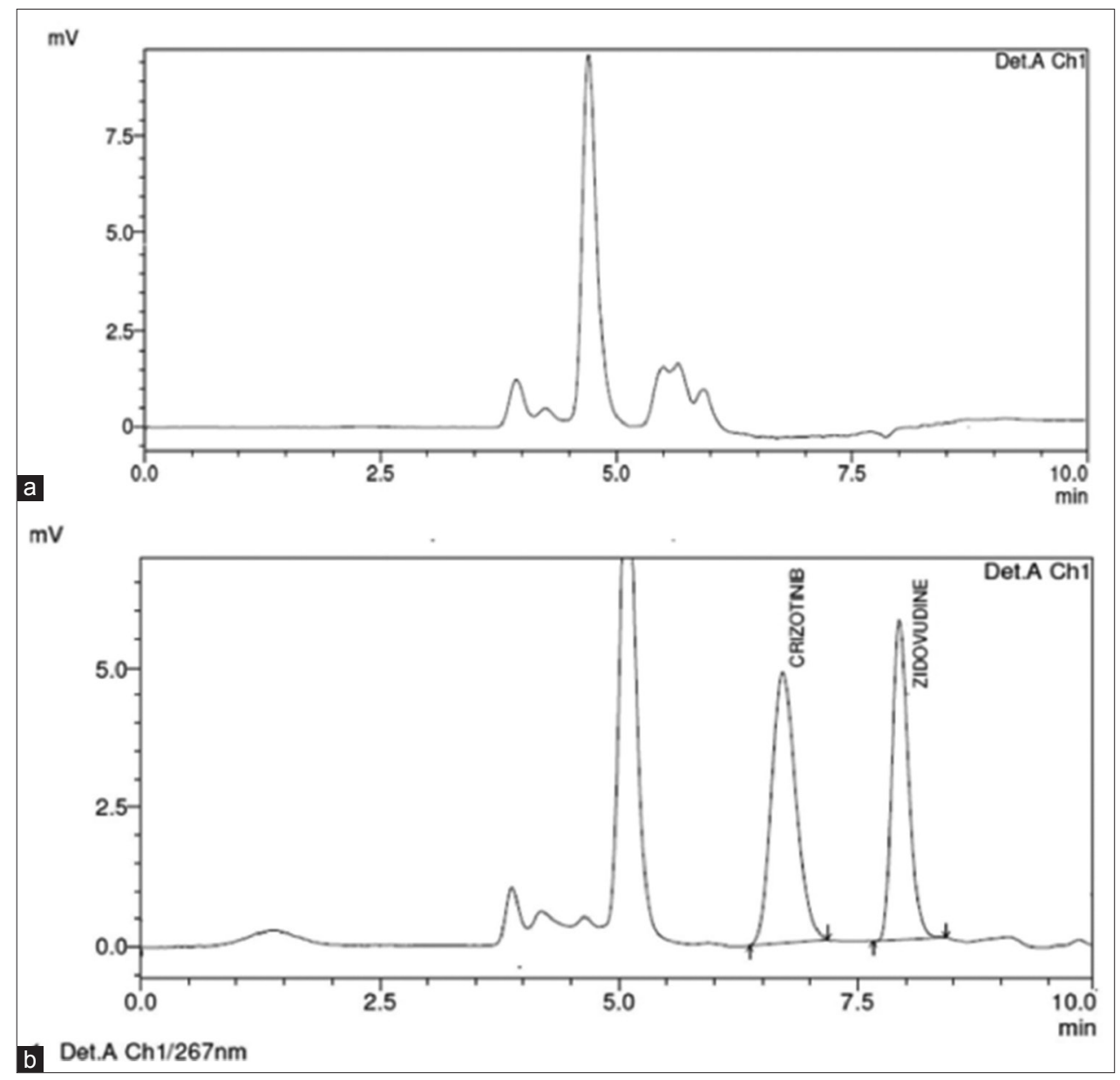

Fig. 2: Chromatogram of (a) extracted blank plasma sample (b) plasma spiked with crizotinib and zidovudine

\section{Linearity}

The linearity was determined from the constructed standard Calibration curve (CC). The upper limit of quantification value was taken as $2041.14 \mathrm{ng} / \mathrm{ml}$ since the plasma concentration of CRZ is lower than this value after its oral administration. Six non-zero samples (20.41, 81.65, $408.23,1224.68,1632.91$, and $2041.14 \mathrm{ng} / \mathrm{ml}$ ) including the lower limit of quantification (LLOQ) $(20 \mathrm{ng} / \mathrm{ml})$ were used to draw the standard CC $(n=3)$. The CC was obtained by plotting chromatographic peak area ratio (CRZ/zidovudine) versus concentration of CRZ (Fig. 3). Samples were prepared and analyzed on the same day. The correlation coefficient $r^{2}$ was found to be 0.9994 (Table 1). The back-calculated concentrations of the calibration standards were within $\pm 15 \%$ of the nominal value, meeting the FDA guidelines.

\section{Accuracy and precision}

Accuracy and precision of the method were evaluated using six replicates of QC samples (LLOQ LQC, MQC, and HQC) as a lower limit, low, medium, and high concentration levels. The samples were analyzed against the CC, and the obtained concentrations were compared with the nominal value. The percentage $\mathrm{CV}$ was calculated forth replicates precision. Both accuracy and precision were studied within a single run (intra) and between different runs (interday), each of them was compared to the calibrations performed. The within-day percentage CV ranged from $1.05 \%$ to $8 \%$, whereas, the between day percentage $\mathrm{CV}$ ranged from $2.0 \%$ to $7 \%$. The intraday accuracy ranged between $97 \%$ and $104 \%$, whereas the interday accuracy ranged between 99 and 106\%. The obtained results (Table 2) indicated satisfactory accuracy and precision of the proposed method.

\section{Recovery}

The percentage recovery of CRZ was measured by dividing the peak area values of extracted QC samples with direct injection of a solution

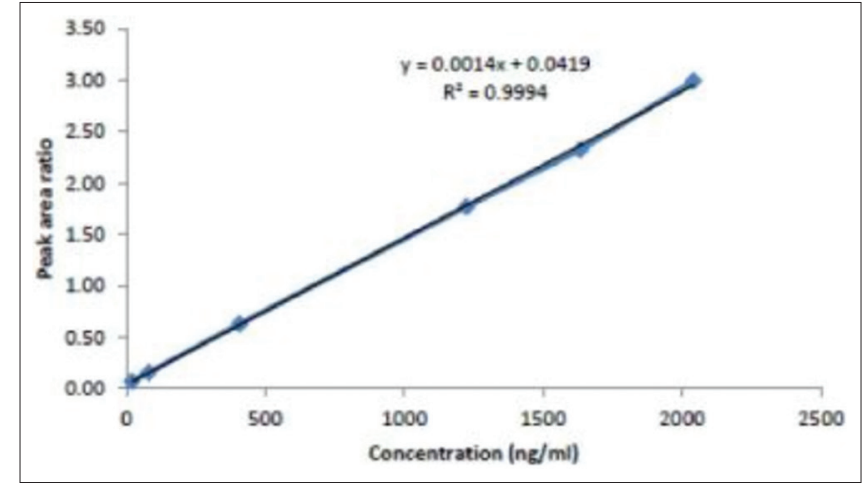

Fig. 3: Calibration curve of crizotinib

Table 1: Linear regression data for CC $(n=3)$

\begin{tabular}{ll}
\hline Parameter & Values \\
\hline Absorption maxima $(\mathrm{nm})$ & 267 \\
Linearity range $(\mathrm{ng} / \mathrm{ml})$ & $20.41-2041.14$ \\
Quantification limit $(\mathrm{ng} / \mathrm{ml})$ & 20.41 \\
Linear regression equation & $\mathrm{Y}=0.0014 \mathrm{x}-0.0419$ \\
Correlation coefficient & 0.9994 \\
Slope & 0.0014 \\
Intercept & 0.0419 \\
\hline
\end{tabular}

CC: Calibration curve

containing the same nominal concentration of compounds as the QC samples in extracted blank plasma. Overall, the results for CRZ 
Table 2: Intraday and interday precision and accuracy $(n=6)$

\begin{tabular}{|c|c|c|c|c|c|c|}
\hline \multirow[t]{2}{*}{ Conc. added (ng/ml) } & \multicolumn{3}{|l|}{ Intraday } & \multicolumn{3}{|l|}{ Interday } \\
\hline & Conc. calculated & $\% \mathrm{CV}$ & $\%$ accuracy & Conc. calculated & $\% \mathrm{CV}$ & $\%$ accuracy \\
\hline 20.41 & 21.23 & 7.47 & 102.68 & 21.50 & 6.35 & 105.85 \\
\hline 995.05 & 1034.73 & 1.19 & 103.98 & 1022.23 & 2.19 & 102.73 \\
\hline 1439.00 & 1437.21 & 2.21 & 99.87 & 1454.18 & 2.01 & 101.05 \\
\hline
\end{tabular}

CV: Coefficient of variation

Table 3: Recovery of CRZ at three concentrations $(n=6)$

\begin{tabular}{lll}
\hline Concentration $(\mathbf{n g} / \mathbf{m l})$ & Mean recovery \pm SD & \% CV \\
\hline 61.23 & $61.56 \pm 3.31$ & 5.38 \\
995.05 & $67.09 \pm 1.96$ & 2.29 \\
1439.00 & $76.20 \pm 2.28$ & 3.10 \\
\hline SD: Standard deviation CV: Coefficient of variation CRZ: Crizotinib &
\end{tabular}

Table 4: Stability of CRZ standard in human plasma under four different conditions

\begin{tabular}{|c|c|c|c|c|}
\hline \multirow[t]{2}{*}{ Stability study } & \multicolumn{2}{|c|}{ LQC (61.23 ng/ml) } & \multicolumn{2}{|c|}{ HQC (1439 ng/ml) } \\
\hline & Accuracy (\%) & CV (\%) & Accuracy (\%) & CV (\%) \\
\hline $\begin{array}{l}\text { Benchtop } \\
\text { stability }\end{array}$ & 101.92 & 4.25 & 99.49 & 1.40 \\
\hline $\begin{array}{l}\text { Freeze and } \\
\text { thaw stability }\end{array}$ & 96.33 & 4.52 & 93.81 & 2.01 \\
\hline $\begin{array}{l}\text { Autosampler } \\
\text { stability }\end{array}$ & 102.79 & 5.78 & 98.56 & 4.66 \\
\hline $\begin{array}{l}\text { Long-term } \\
\text { stability }\end{array}$ & 97.71 & 1.60 & 97.44 & 3.64 \\
\hline
\end{tabular}

absolute recovery from human plasma were tested at three different concentration levels (LQC, MQC, and HQC) were $61.56 \%, 67.09 \%$, and $76.20 \%$, respectively. The results of the recovery studies of CRZ are represented in Table 3. The mean recovery of CRZ was $68.29 \%$ with a coefficient of the variation of $3.80 \%(n=3)$. Internal standard recovery at $2.5 \mu \mathrm{g} / \mathrm{ml}$ of zidovudine was $56.12 \%$ with a coefficient of the variation of $1.10 \%$.

\section{Stability}

Analysis of the stock solutions of CRZ and IS in methanol was stable for 30 days at $2-8^{\circ} \mathrm{C}$ and at room temperature for $6 \mathrm{~h}$, more than $97.5 \%$ of CRZ remained unchanged, based on peak areas in comparison with freshly prepared solution of CRZ. This suggests that the CRZ in standard solution is stable for at least 30 days when stored at $2-8^{\circ} \mathrm{C}$ and for $6 \mathrm{~h}$ at room temperature $[17,18]$. Stability of CRZ in plasma samples was investigated with spiked samples at two different concentration levels. Benchtop stability of CRZ in plasma was investigated at LQC and HQC levels. This revealed that the CRZ in plasma was stable for $6 \mathrm{~h}$ at room temperature. It was confirmed that repeated freezing and thawing (three cycles) of plasma samples spiked with CRZ were assessed by analyzing three replicates of $\mathrm{QC}$ at low and high level did not affect the stability of the drug. The freeze-thaw stability of CRZ after three cycles was $96.33 \%$ and $93.81 \%$ at low and high concentrations. Longterm stability of the CRZ in plasma at $-20^{\circ} \mathrm{C}$ was also performed after 15 days of storage at LQC and HQC levels, and similarly, autosampler stability was studied following $48 \mathrm{~h}$ storage at $4^{\circ} \mathrm{C}$ in the autosampler tray with control concentrations. Further, no significant change in the chromatographic behavior of CRZ and IS was observed (Table 4). The above results indicated that the CRZ was stable under all conditions studied.

\section{CONCLUSION}

A selective, accurate, and precise RP-HPLC method for the estimation of CRZ in human plasma was successfully developed. The method met the validation criteria laid down by the US-FDA guidelines. The HPLC technique based on UV detection is suitable for the determination of small amounts of CRZ with good accuracy and reproducibility. Simple sample preparation procedure and relatively short chromatographic run time make this method suitable for processing multiple samples in a limited amount of time for pharmacokinetic studies. Hence, the developed method can be applied to pharmacokinetics studied and therapeutic drug monitoring in humans.

\section{ACKNOWLEDGEMENT}

The authors are thankful to Mr. Santosh Tata, Pharmaceutical Research and Development Laboratory, Corpuscle Research Solutions, Visakhapatnam, India, for providing the necessary facilities to conduct research work.

\section{AUTHORS' CONTRIBUTION}

Dr. Srinivasa Rao Atla designed and directed the project to his research scholar Ms. Baby Nalanda R who has performed the experimental work and contributed in preparing the manuscript. Dr. Gowri Sankar supervised the research work.

\section{CONFLICTS OF INTEREST}

We wish to confirm that there are no known conflicts of interest associated with this research work.

\section{REFERENCES}

1. Iams WT, Lovly CM. Anaplastic lymphoma kinase as a therapeutic target in non-small cell lung cancer. Cancer J 2015;21:378-82.

2. Solomon BJ, Mok T, Kim DW, Wu YL, Nakagawa K, Mekhail T, et al. First-line crizotinib versus chemotherapy in ALK-positive lung cancer. N Eng J Med 2014;371:2167-77.

3. Shaw AT, Kim DW, Nakagawa K, Seto T, Crinó L, Ahn MJ, et al. Crizotinib versus chemotherapy in advanced ALK-positive lung cancer. N Engl J Med 2013;368:2385-94

4. Li C, Alvey C, Bello A, Wilner KD, Tan W. Pharmacokinetics of crizotinib (PF-02341066) in patients with advanced non-small cell lung cancer (NSCLC) and other solid tumors. J Clin Oncol 2011;29:13065.

5. Herbrink M, de Vries N, Rosing H, Huitema AD, Nuijen B, Schellens JH, et al. Development and validation of a liquid chromatographytandem mass spectrometry analytical method for the therapeutic drug monitoring of eight novel anticancer drugs. Biomed Chromatogr 2018; 32:1-9.

6. Sparidans RW, Tang SC, Nguyen LN, Schinkel AH, Schellens JH, Beijnen JH. Liquid chromatography-tandem mass spectrometric assay for the ALK inhibitor crizotinib in mouse plasma. J Chromatogr B 2012; 905:150-4.

7. Wani T, Lqbal M, Darwish I, Khalil N, Zargar S. Development and validation of sensitive UPLC-MS/MS based method for the estimation of crizotinib in human plasma. Dig J Nanometer Biostruct 2014; 9:693-704

8. Huang X, Cai J, Wang X. LC-MS determination of crizotinib in rat plasma and it application to a pharmacokinetic study. Lat Am J Pharm 2014;33:1188-92.

9. Michael SR, David CT, Alberto B, Clinton FS. Determination of 
crizotinib in human and mouse plasma by liquid chromatography electrospray ionization-tandem mass spectrometry (LC-ESI-MS/MS). J Chromatogr B 2014;960:151-7.

10. Khalil NY, Wani TA, Darwish IA, Al-Majed RA. Highly sensitive HPLC method with non-extractive sample preparation and fluorescence detection for determination of crizotinib in human plasma. Lat Am J Pharm 2014;33:1019-26.

11. Hany WD, Ahmed HB, Ibrahim AD. Enhanced spectrofluorimetric determination of the multitargeted tyrosinase kinase inhibitor crizotinib in human plasma via micelle-mediated approach. Trop J Pharm Res 2016;15:2209-17.

12. Vijayakumar B, Suman E, Sreekanth G. Estimation of crizotinib in capsule dosage form by RP-HPLC. IOSR J Pharm Biol Sci 2016; 11:93-103.

13. Guidance for Industry. Bioanalytical Method Validation. Rockville, MD: U.S. Department of Health and Human Services, Food and Drug Administration Center for Drug Evaluation and Research; 2001
14. Singh Y, Hidau MK, Misra A, Kushwaha HN, Tiwari A, Sharma AK, et al. UFLC method development and validation of a novel triethylamine containing thiophene S006-830-an antitubercular molecule and its application to pharmacokinetic and bioavailability studies in SD rats. Drug Test Anal 2015;7:721-6.

15. Togami K, Fukuda K, Yamaguchi K, Chono S, Tada H. Facile and sensitive HPLC-UV method for determination of nintedanib in rat plasma. Int J Pharm Pharm Sci 2018;10:133-7.

16. Kraak JC, Crombeen JP, Brelmer DD, Spewer P. Sample Pretreatment in Bio-Analysis. Amsterdam: Elsevier; 1987. p. 123-35.

17. Madhavi S, Rani AP. Bioanalytical method development and valiation for the determination of sofosbuvir from human plasma. Int J Pharm Pharm Sci 2017;9:35-41.

18. Jinesh BN, Bannimath G. Simultaneous estimation of clopidogrel and atorvastatin in human plasma using bio-analytical RP-Ultra fast liquid chromatographic method. Int J Curr Pharm Res 2015;7:30-5. 